\title{
The Time of the Animal
}

\author{
BRETT BuCHANAN
}

In the essay "The Animal That Therefore I Am (More to Follow)," Jacques Derrida proposes an untimely reading of Heidegger and animals. As he has done numerous times in his writings, Derrida suggests that he will have to return to a more careful reading of Heidegger, this time on animals, a topic that nevertheless received continued attention throughout his career. Here he writes:

Although I must put off until later a patient reading and interpretation of the systematic and rich text that, in 1929-30, following Being and Time, Heidegger devoted to the animal, I note the following in anticipation of it here, having just spoken of time before time: one of the rare times, perhaps the only time (that needs checking) that Heidegger names the animal in Being and Time, a text that is also in its own way a treatise that seeks to be non-Christian, concerning a certain fall of the Dasein, it is in order to admit to a difficulty that will be saved for later (my hypothesis is this: whatever is put off until later will probably be put off for ever; later here signifies never). What is this difficulty? That of knowing if the animal has time... (391)

Despite this hint of somber foreshadowing, Derrida never returned to Heidegger and animals, at least not in any sustained manner. ${ }^{1}$ Following his lead, however, I too am curious about the status of animal time, so I heeded his call and checked the references. In a certain sense, animals need to be counted. Two references to the animal rationale notwithstanding, there are actually three appearances of the animal in all of Being and Time. Depending on your inclination, this fact alone may or may not be surprising. What might come as slightly more interesting is that each indication of the animal is tied up with the question of time. Admittedly, this too might not 
call for special attention given that 'time' is, after all, a principal theme of the text. But this congruence between animals and time really ought to make us pause for a moment, if for no other reason than because it has not received anywhere near the attention that it is due. While Heidegger's characterizations of animals are often defined by a lack-poor in world, lack of language, lack of 'hands', a non-death, etc.-_little attention has been paid to time itself. ${ }^{2}$ This has been the case despite Derrida's brief query on the significance of time, a suggestion that is echoed by Françoise Dastur in her claim that "the guiding thread in the analysis of animality is ... a transcendental understanding of finitude" (Heidegger et la question anthropologique, 62). ${ }^{3}$

While both Derrida and Dastur hint at the importance of this theme, neither continued with its examination since their immediate interests lay elsewhere. In the following paper I wish to highlight a few spots where Heidegger addresses the theme of animality and time in order to underscore the ambiguity in which he leaves these passages. By moving between Being and Time and the more familiar descriptions of the animal in The Fundamental Concepts of Metaphysics, I want to suggest that Heidegger's continual deferral on the problem of animal time is the reason that he himself remains unsatisfied with his own theses concerning the being of the animal. The three references in Being and Time prepare us for the respective themes of time, death, and the temporality of organic self-production, each of which is conspicuously postponed in his later analyses on animal ontology. To this end, his ontology of the animal is itself incomplete.

\section{Who has time for animals?}

The animal shows itself to be an elusive subject throughout Heidegger's writings, but it ought to be noted that the dilemma is already evident within Being and Time. Prior to Being and 
Time the animal is surprisingly not as much of a problem, at least concerning the concept of world. As late as 1925 we can observe Heidegger more or less equating animal being with human Dasein when he notes that even animals have a world. In a series of lectures on Wilhelm Dilthey, Heidegger remarks "we miss the essential thing here if we don't see that the animal has a world. In the same way, we [Dasein] too are always in a world in such a way that it is disclosed for us" ("Dilthey's Reasearch" 163). ${ }^{4}$ He will later retract such a claim regarding the animal's 'having' a world, but it is worth noting insofar as it underscores that by the time of Being and Time, the animal has become more of an issue. Indeed, it is precisely the fact that Heidegger acknowledges the problem of the animal—which he will do a few times, as we shall see—only in order to turn away from it, that proves so perplexing. That is, he will often acknowledge that the animal proves to be difficult, but unlike his approach to other difficult problems he will all too often leave the theme of animal time mired in ambiguity. Beginning with the third and final appearance of animals in Being and Time (\$68) - I will work backwards through the three appearances-we can observe this characteristic gesture: "It remains a problem in itself to define ontologically the way in which the senses can be stimulated or touched in something that merely has life [einem Nur-lebenden], and how and where the Being of animals [das Sein der Tiere], for instance, is constituted by some kind of 'time' [eine 'Zeit']" (396/346). Thus, the problem is posed: is the being of the animal grounded in time? Are animals fundamentally temporal? As soon as the problem is posed, however, it disappears just as quickly. The animal does not return in the text after this reference.

Before looking at this further, we should first recall Heidegger's dismissal of any and all biological interests in the opening sections of his treatise, where the biological, along with the psychological and anthropological, are swept aside by the movement to ground the existential 
analytic of Dasein. In order to work out the question of the meaning of being - the proposed task of the text-Heidegger's thought leads through that being or entity for whom the question of being is at issue. Thus the emphasis throughout Being and Time is one of describing how humans exist such that they can even be considered as that being that they are. Heidegger repeats throughout that before any question can be entertained about 'what humans are' (as found in the sciences, for instance), the a priori condition for how human Dasein is in the world must first be disclosed. Thus even though Being and Time is purportedly an inquiry into the meaning of being, the majority of the text, in its famously incomplete state, is an account of how Dasein discloses itself in the world. Any biological consideration—such as the notion that humans, considered ontically, are biological animals-is pushed aside. And yet the biological animal returns at various junctures in Being and Time, presumably to remind us that we are not to think of Dasein's ontological status as akin to the rational animal of tradition, and certainly not as some biological entity. But there may be something more to the appearance of the animal other than to provide a clear juxtaposition to Dasein. On the one hand, then, the ontology of Dasein is clearly distinguished from its own ontic basis as a biological being, but on the other hand, there is the issue of "how and where" (and not "how and whether") animals themselves might be ontologically constituted by time. ${ }^{5}$

Now why is this important? The question of time and temporality, as we well know, provides the ecstatic ground of Dasein's being. Time makes up the "primordial ontological basis" and "primordial meaning" of existence that is proper to Dasein (277-78/234-35). Working toward his account of time, the being of Dasein is defined by Heidegger as that of "care," by which he articulates the unity of our being-in-the-world as one wherein we ontologically transcend our ontical condition. We are always ahead of ourselves as being-in-the-world 
(237/192) and, as such, temporality is the transcendental basis by which Heidegger defines

Dasein's being. ${ }^{6}$ Even more pointedly, Heidegger remarks in his 1924 lecture "The Concept of Time" that "Dasein is time" and "time is Dasein" (20E). ${ }^{7}$ In contrast, Heidegger will later define the essence of the animal in his 1929-30 course by that of "captivation" (FCM 248) in order to underscore precisely the inability of animals to transcend their condition. Whereas the being of human Dasein is one of disclosure and unboundedness, the being of animals is one of partial closure and being bound and absorbed in themselves. If it is the case, however, that animals are also granted time and temporality—even if it is only "some kind of "time", (and we need to note that 'time' is within scare quotes) — this may give us reason to pause regarding the ontological privilege accorded to ourselves as Dasein, as well as reason to re-consider the often negative characterization of animal being as deficient in comparison. Furthermore, the time of the animal would seem crucial to any ontological pronouncement regarding the being of the animal as such. There is much at stake, therefore, if animals are constituted by time.

This provocation also grabs the attention of Didier Franck, who, in his essay "Being and the Living," problematizes the privilege accorded to Dasein:

But can the temporal constitution of life and the living be considered a separate, that is to say, in the end, a secondary problem? ... Indeed, if the being of an animal were to be excluded from time, Being itself would thereby lose the exclusivity of its temporal meaning, and, if we live only by being incarnate in a body that testifies to our kinship with the animal, the ontological detemporalization of the animal would imply that the living incarnate that we are is existentially inconceivable, and that we must abandon the name of Dasein. (137)

What Franck discerns in Heidegger's ontology is "the total exclusion of [Dasein's] live animality"; Dasein is no ordinary living thing. Indeed, Dasein is so cut off from its very own living flesh that Franck concludes, rather emphatically, that "never in the history of metaphysics has the Being of man been so profoundly disincarnated" (146). ${ }^{8}$ Such a claim concerning 
Dasein's presumed lack of bodily being is a familiar one, from the early critiques of Karl Löwith to Alphonse de Waelhens's succinct claim that "in Being and Time ... one does not find ten [lines] concerning that of the body" (xix). ${ }^{9}$ Despite these enumerations, this does not mean that the body is absent from Heidegger's thought, no more than the lack of the animal's presence in Being and Time means that the animal is absent. What it does suggest is that the existential analytic of Dasein has come at a cost, namely the cost of life itself. In order for Dasein to be itself, it cannot be defined ontologically as anything akin to the living animal. ${ }^{10}$ But while critical attention is usually paid to bringing Dasein back down to nature, so to speak, I'm more interested in how Heidegger flirts with the possibility of animal being with respect to temporality. Flirts with it, that is, insofar as he does not rule out the possibility of animal temporality. Thus far we have witnessed that the living animal poses an ontological conundrum, and that it is formulated in terms of time. What are we to make, then, of the other two appearances of animals? Might the remaining two passages offer any indication concerning how we ought to consider animal time?

\section{Time of perishing}

The second appearance of animals within Being and Time $(\$ 49)$ is a curious one because Heidegger raises animals not just in the context of life, but he does so, more importantly, with respect to death. We are familiar with the importance of being-towards-death in Heidegger's work, for it provides an expository domain for considering the totality or wholeness of Dasein. Insofar as human Dasein is characterized ontologically as being-ahead of itself, Heidegger acknowledges that Dasein is not yet complete; or, otherwise put, Dasein is a whole inasmuch as its own nothingness is subsumed within its being a whole as being-towards-death. As such, death allows a more proper consideration of ecstatic temporality. In terms of animals, however, we 
might think that because they are defined as the living — even if merely living — that death would play a significant role. As the example of mere life, surely animals must also be subject to death as well. Not necessarily:

Even Dasein may be considered purely as life. When the question is formulated from the viewpoint of biology and physiology, Dasein moves into that domain of Being which we know as the world of animals and plants. In this field, we can obtain data and statistics about the longevity [Lebensdauer] of plants, animals and men, and we do this by ascertaining them ontically. Connections between longevity, propagation, and growth may be recognized. The 'kinds' of death [Die 'Arten' des Todes], the causes, 'contrivances' and ways in which it makes its entry, can be explored. (290-91/246)

The domain of Being that is said to belong to animals and plants is one of longevity, propagation, and growth, one of numbers and calculations. The longevity and duration of animal life would be ascertainable through a certain kind of temporal enumeration, but this is far from the ontological temporality that Heidegger will elicit from the being of Dasein. ${ }^{11}$ We will return to some repercussions of viewing animals as ontic things that can be counted and used, and specifically what this might mean in terms of temporality. For the moment, however, it is what Heidegger calls the "'kinds' of death" (where 'kinds', like 'time', is in scare quotes) associated with animals that I wish to highlight.

Inasmuch as the animal has been introduced as the mark or sign of the merely living, we can guess about what Heidegger is speaking when he makes the following claim: "Dasein's going-out-of-the-world in the sense of dying must be distinguished from the going-out-of-theworld of that which merely has life [des Nur-lebenden]. In our terminology the ending of anything that is alive, is denoted as 'perishing' [Verenden]" (284/240). 'Perishing' is one of the 'kinds' of death, though we are to understand that it isn't really death after all. Not ontologically, at any rate. Rather, it is as it sounds: a coming to an end. As a calculable ontic being, we could say that that living thing's number has been called. Or, as Derrida puts it in Aporias, the living 
thing "eventually kicks the bucket" (30-31). By contrast, it suffices to recall that "Dasein never perishes" (290/247). Taken ontically, Dasein can "demise [Ableben]" as a medical or biological being; taken ontologically, Dasein can die (stirbt) by virtue of its being-towards-death, due to its relation to death as something before it, as a relation to the possibility of the impossibility of its very being. It also ought to be noted that Heidegger puts scare quotes around 'kinds' of death, rather than around 'death' itself, as one might otherwise expect. Is he perhaps suggesting that there really aren't different kinds of death, that there is really only death plain and simple, and that to say that there are different 'kinds' is bending the truth just a little?

Rather than following Heidegger's thought on being-towards-death, I would rather draw our attention to the notable exclusion in these pages, namely that of the animal. It is not so much that the animal goes unnoticed, but that the animal's relation to death is covertly passed over. As before, the ontological analysis of death takes precedence over the "biological-ontical exploration of death," which really belongs to the territory of longevity, propagation, and growth. Nothing is said explicitly about animals and death, but Heidegger's meaning is still heard: while Dasein dies, we are left to understand that animals, as merely living things, perish. Their lives come to an end, stop. Again, Heidegger does not say this explicitly in Being and Time. Perhaps he didn't need to. Either way, however, he will have occasion to formulate this position more explicitly in his 1929-30 lecture course, where he is at once more clear and yet somehow more elusive as well.

At the very end of his long analysis on animal life in The Fundamental Concepts of Metaphysics - an analysis that occupies the central part of this lecture course-Heidegger raises two issues that, as he says, "we deliberately avoided." One issue concerns the motility of animals. The other issue concerns death. On the topic of death, Heidegger is now rather succinct 
in his conclusions: "Is the death of the animal a dying or a way of coming to an end? Because captivation belongs to the essence of the animal, the animal cannot die in the sense in which dying is ascribed to human beings but can only come to an end" (388/267). Based on his claims regarding death in Being and Time we are in a way prepared for this curt assessment. Yet a few questions emerge nonetheless: why, after devoting several months of his lecture course to the analysis of animal life, does he raise death only at the very end as something deliberately avoided? In talking about the essence of life-where animals constitute the example par excellence-why avoid the question of death? Why do so, moreover, when death is so important (primordial and "superordinate" even) to the analysis of Dasein? And why avoid this topic deliberately, that is to say, not accidentally, but intentionally? It is a curious section of his course, to put it mildly. For Heidegger does not so much omit death from his analysis (for he has just now invoked it), as neglect it insofar as he names death as something specifically to be avoided. But why?

One could even wonder whether death, in its ontologically significant sense, matters as much as it does. For instance, Derrida offers the following assessment in his reading of Heidegger on being-towards-death:

Against, or without, Heidegger, one could point to a thousand signs that show that animals also die. Although the innumerable structural differences that separate one 'species' from another should make us vigilant about any discourse on animality or bestiality in general, one can say that animals have a very significant relation to death, to murder and to war (hence, to borders), to mourning and to hospitality, and so forth, even if they have neither a relation to death nor to the 'name' of death as such, nor, by the same token, to the other as such, to the purity as such of the alterity of the other as such. But neither does man, that is precisely the point! Nor even does man as Dasein, assuming one that one could ever rigorously say man and man as Dasein. (Aporias 75-76)

Through his reading, Derrida calls into question the very possibility of being-towards-death as something that Dasein can be towards: death as my ownmost possibility, as "mine," is 
nevertheless something that I can never "have." Insofar as death is "the possibility of the impossibility of Dasein," Derrida relinquishes Dasein of the possibility of ever claiming death as "my death." Thus, the relation to death, he claims, is also one of perishing or demising. Neither the animal, nor Dasein, has a relation to death as such.

The problem of the animal again comes back to the ascription of time, that theme that constantly surrounds animals but that is never really addressed. Instead, what we have seen so far is that, firstly, the "kind of "time"" that belongs to animals remains a problem, and secondly, animals do not die because they belong to that ontological domain of the merely living which is one of longevity, propagation, and growth. They are thus more akin to a number than to Dasein's anticipation of its own death.

\section{The time of the organic body}

The first appearance of animals within Being and Time $(\S 15)$ also occurs in relation to time, and it is just as dubious as the previously noted references. I quote:

In work there is also a reference or assignment to 'materials': the work is dependent on leather, thread, needles, and the like. Leather, moreover is produced from hides. These are taken from animals, which someone else has raised. Animals also occur within the world without having been raised at all; and, in a way, these beings still produce themselves even when they have been raised. So in the environment certain beings become accessible which are always ready-to-hand, but which, in themselves, do not need to be produced. (100/70, translation modified)

Now aside from the similarities to the previous passage $(\$ 49)$ —here we see that animals are described as having the ontological character of being ready-to-hand-what I actually wish to draw our attention to is the comparison of animals with tools and equipment and its relation to time. 
Time is not obvious from this passage alone, but the leather of which Heidegger speaks is couched within a discussion of the clock. One analogy is particularly noteworthy: "The shoe which is to be produced is for wearing (footgear); the clock is manufactured for telling the time" (99/70). In such an instance, animals are similar to other natural things that are ready-to-hand within everyday work: in the same way that hammers, tongs, and needles refer to steel, minerals, and so on, we are led to understand that such things as shoes and coats refer to animals as readyto-hand for our materials. Moreover, we are reminded that they are even raised for this purpose. Much could be said about this parallel, but I wish to keep our attention directed toward the idea that animals are also, as he notes, self-producing. So while there are similarities between the animal, on the one hand, and metal, steel, and so on, on the other, there is also a very large difference: animals produce themselves. Heidegger's example of the animal is simple enough insofar as he is describing how 'nature' is discovered through the things we make use of; just as steel is discovered through the hammer, and the position of the sun is found behind the uses of a clock, so too is the animal already ready-to-hand behind the shoes on our feet. There is an affiliation of animals with equipmental being, therefore, but only in that animals reveal themselves as part of the natural domain as self-producing. They are not tools first and foremost, but 'hidden' as being ready-to-hand behind and within things that are produced. Thus it is not just that animals are mentioned in the context of Dasein's work in and on nature, which is significant in its own right, but that animals, as self-producing, presuppose our own productive work. Furthermore, as self-producing, animals have their own temporal dimension that is withheld from such lifeless things as hammers, stones, and even clocks. For example, the stone, as Heidegger claims in his 1927 course The Basic Problems of Phenomenology, has no relation to time whatsoever: "we do not call a being like a stone temporal, even though it moves or is at 
rest in time. Its being is not determined by temporality" (271). No mention is made of the animal in this context, and perhaps for good reason. But while Heidegger abstains from any temporal pronouncement, he has nevertheless made a connection between animals, tools, and time. The longevity of animal life - as one of self-production - entails some kind of temporality.

This connection allows us to lead more directly toward an encounter with animal time, and, as was the case with the previous citations from Being and Time, we find this theme explored at greater length in the 1929-30 lecture course, The Fundamental Concepts of Metaphysics. The three passages noted above indicate that the being of the animal is implicated in some 'kind' of time, that animal life is one of duration and longevity but not of being-towardsdeath, and finally that animals, unlike other things ready-to-hand, are self-producing. One of Heidegger's concerns in 1930 is to avoid reducing the being of animals to a mechanistic or vitalist interpretation that would see the animal body as akin to a machine, and animal organs as akin to cogs in the machine. Etymologically, the term "organism" relates back to the Greek "organon" and "instrument" (213 passim), but even in their biological being animals have an essential relationship to time that instruments and tools do not. Just as with many of his other comments on these issues, Heidegger again flirts with the question of animal time only to leave it suspended:

The organs as established features, as in the case of the higher animals, are bound to the lifespan [or longevity, die Lebensdauer gebunden] of the animal, i.e., not merely in the first place to time as an objectively definable period during which the animal lives. Rather the organs are bound into and are bound up with the temporal span [die Dauer] which the animal is capable of sustaining as a living being. Even if we cannot pursue here the problem concerning this relationship of the organism and its organs to time [zur Zeit], it is already clear from such general reflections that organ and equipment relate precisely to time in fundamentally different ways. And it is this which first grounds an essential distinction in their respective manners of being, if we accept that the temporal aspect [der Zeitcharakter] is metaphysically central for each manner of being. (224-25) 
There are a number of things to comment on here. We could point to how Heidegger raises a seemingly crucial issue-how organisms and organs relate to time, and how time is central to the being of animals-only to not pursue it. We could notice how the character of time might be that which grounds the essential distinction between organs and equipment. Similarly, it would not be an exaggeration to suggest that time might provide an essential distinction between animals and Dasein. This would not be a great leap since Heidegger already acknowledges a difference between the organs of "higher" animals and those of presumably 'lower' animals. For example, the "structureless and formless" lives of "tiny protoplasmic creatures" have organs, but due to their lack of a firm shape, "their organs are therefore temporary organs [Augenblicksorgane]" (FCM 224). But if Heidegger makes a distinction here between higher and lower animals (to say nothing of Dasein that stands outside of either category), then he is also making a temporal distinction, which might also mean an essential distinction in their manners of being. The organs are bound up within the temporal span of the animal, but if the organism in question keeps destroying its own organs, or assimilates another cell into itself, or let us say, splits itself in two, then we might have a different notion of time at play-not just as an "objectively definable time," but in terms of the lifespan or longevity of the animal as a whole. We could also point to the fact that the being of animals is constituted in these lectures, in contrast to Being and Time, by some sort of time, and this time without the scare quotes. Animals have a relationship to time, even one that might very well be essential to their manner of being. Perhaps we ought to claim, as Franck does, that "it is solely the determination of the rapport of the organism and the organs to time that will in the end decide the ontological meaning of life" (139). 
What does this leave us with? Unsurprisingly, the question is left unresolved. Despite every indication that Heidegger gives to warrant our abandonment of a more fundamental understanding of time in the case of animals, he returns to the open-endedness of these issues. Every sign suggests that he wants to make a firm decision and make a clean break between the ontology of the animal and Dasein with respect to time, but then he does not. The question of animal time is always put off. As one last example, in a section entitled "The incompleteness of our present interpretation of the essence of the organism," Heidegger notes that some biologists have started to refer to organisms as historical beings (such as Theodor Boveri in The Organism as a Historical Being). If animals are born, mature, age, and die (“death of animals"), even if only, under the worst scenario, as a statistical number, then this might also suggest that they are historical.

What kind of history [Geschichte] do we find in the life process of the particular individual animal? What kind of history does the animal kind, the species, possess? ... Can we and should we speak of history at all where the being of the animal is concerned? If not, then how are we to determine this motility? You can see that one question gives rise to others, that one question is more essential than another, that each question is poorer with respect to its answer than the next. (FCM 265-66).

Heidegger is not merely addressing the idea that animals are in time or that one could make a history of them, any more than his account of Dasein's temporality and historicity consists of merely 'being in time'; if this was all he was saying about animals, we would not find a continual deferral of the problem. Rather, as he alludes to in Being and Time, and as we discover again in his lengthy consideration of animal ontology in The Fundamental Concepts of Metaphysics, the problem is precisely that of the temporal character of animal being.

From one perspective, William McNeill offers the clearest insight into Heidegger's 192930 reading by suggesting that animals are not temporal insofar as they are incapable of holding 
forth in the presence of things (239). It would seem that animals do not hold a free stance over and against the world; they are incapable of attaining any detachment, or any permanence, with respect to things, and thus lack a specific temporal bearing. This is surely a strong assessment, particularly in terms of the importance of worldhood. Inasmuch as animals are found to be captivated and transfixed by their environment-and are thus unable to comport themselves either to things or to the being of things or to the immanence of death-Heidegger remarks that they are "poor in world." As McNeill notes, being in a world entails an ability to stand outside of the presentation of things by maintaining a permanent stance over and against the temporal flow. Thus the account of the animal's being poor in world involves a temporal pronouncement of sorts, namely that animals do not transcend their relations to things but remain immured within their captivated being.

But since Heidegger's primary interest in the later lecture course lies not with time but with the concept of world, it is still unclear how the ontological significance of animal time can be considered outside of or beyond the issue of worldhood, if it can be. That is, Heidegger's pronouncements on the being of the animal derive mainly from his analysis of how they relate to their environments, and not from a treatment of the temporal character of the animal itself. Despite his claim to be conducting a "comparative examination" between animals and human Dasein-a comparison between modes of being that are ultimately found to be beyond comparison, separated by an unbridgeable abyss (FCM 282)-Heidegger's examination of the animal comes up short: while the analysis of Dasein pushes through the notion of being-in-theworld to reveal the temporal dimension of Dasein's being, the analysis of the animal remains fixed at the level of being poor in world. There is no further push to uncover animal time. In fact, it is expressly avoided. 
It is not my intention to suggest that animals have something akin to the ecstatic temporality of human existence. Nor am I inclined to diminish Dasein's ontological status, as has been suggested by Franck. Part of the interest in Heidegger's comparative examination is that he does not simply blur the differences between humans and all other animals. As he remarks, there is an ontological difference between Dasein and all other entities. But based on the themes raised in Being and Time, and again in The Fundamental Concepts of Metaphysics, all signs indicate that the being of animals has not been treated to the same degree as Dasein. On the most primordial of issues, an account of animal time is withheld. As such, his universal account of the ontology of the animal is somewhat suspect, not only because his analysis remains confined to the concept of world but also because it reduces all animals to an ontological homogeneity that has not been, as he himself admits, temporally examined. For instance, while we discover an ontological statement of essence concerning "all animals, every animal" (FCM 186)_all animals are essentially captivated, thus all animals are assimilated into an ontological equivalence-we are also led to believe that there may be an essential temporal distinction between so-called 'higher' and 'lower' animals with respect to their organic lifespan. If this is the case, the essence of all animals may not be so universal.

The three explicit indications of the animal in Being and Time - the problem of 'time', their 'kind' of death, and the animal as self-producing - therefore remain problematic within his most sustained examinations of animal ontology. Without addressing this overarching theme of time - a theme that is central to his thinking overall—we can see that his comments in Being and Time anticipate and even foreshadow what is strikingly absent from his later accounts. This is all the more evident considering that the lengthy treatise on animality in 1930 follows quickly upon Heidegger's prolonged examination of boredom and the temporality of Dasein. Further, time is 
evident in its inconspicuousness despite the analogy between finitude and animality where each occupy the "middle" and unifying root between two terms, finitude between the question of world and individuation (FCM 170), and the animal between the stone and Dasein (185). While boredom and finitude are each raised immediately prior to the section on animal ontology, they likewise reappear immediately afterward (281-283), as though they bracket (and are thereby bracketed out of) Heidegger's inquiry into the essence of animals. If it is the case that his interpretation of animal being is "still incomplete" (265), still of a "limited character" (267), and still "remain[s] as a problem" (273), I would venture that this is because of the continually deferred issue of animal temporality. As we have seen, this theme is often hinted at but never resolved. And not only is it unresolved—this idea of a resolution is unbecoming to Heidegger's thinking anyway-it is never properly brought to thought in the first place. While we discover many pronouncements regarding animals throughout his writings- that they are poor in world, lack language, do not experience death, have no hands, and so on-the time of the animal is notably withheld. Avoided, one could say. Even the rock received its acknowledgement as being atemporal. As for the animal? Its temporal character is not discovered. Inasmuch as this is the case, we should be hesitant, as Heidegger himself was, in taking his account of the being of the animal as conclusive. 


\section{Notes}

${ }^{1}$ I know of no sustained reading by Derrida on this lecture course outside of the present essay and brief remarks here and there, such as in Of Spirit: Heidegger and the Question and "Eating Well', or the Calculation of the Subject." There are many other essays that deal with Heidegger and animals, in one combination or another, but not of this 1929-30 lecture course.

2 Of the numerous pieces dealing with Heidegger and animals, more recent surveys of the literature can be found in Stuart Elden's "Heidegger's Animals" and Matthew Calarco's "Heidegger's Zoontology." There are many other articles that offer more specific readings, but these are the most recent and the most broad in scope. Neither, however, entertains the importance of time.

${ }^{3}$ The theme of the animal does not appear in Dastur's earlier work, Heidegger and the Question of Time.

${ }^{4}$ One can observe a similar statement in the 1925 lecture course History of the Concept of Time: Prolegomena. By 1930 Heidegger will famously declare animals to be "poor in world," an obvious change from his earlier sentiments.

5 In a translators' note, Macquarrie and Robinson note that earlier versions of Sein und Zeit (earlier than the seventh edition, at any rate) had "wie und ob" rather than the revised "wie und $w o$ " in this passage on animals. Thus, it appears that Heidegger's uncertainty concerning animals and time is no longer whether they have time ("how and whether"), but rather how and where in their being they might have time. As a further note to this revision, we might nevertheless notice that Heidegger inserts wo (which has spatial connotations) as opposed to the wenn or wann of time (which he uses elsewhere concerning Dasein).

${ }^{6}$ In a footnote to the 1929 essay "On the Essence of Ground," Heidegger clearly establishes the importance of "transcendence" in Being and Time, a term that receives attention in lecture courses surrounding Being and Time's publication, but does not receive much development in the text itself (125, fn.66).

7 A comparison might be made to Merleau-Ponty's remark that "I am myself time" (421) in his Phenomenology of Perception, wherein he is actively reading Heidegger on time.

${ }^{8}$ We could also recall here Derrida's remarks in Of Spirit, among which is his reading that "there is no animal Dasein" (56).

${ }^{9}$ With a bit more accuracy, David Krell has counted the number of times der Leib appears (22) versus der Körper (26) in his Daimon Life (53-54). More recently, Frank Schalow has attended to the issues of the body in The Incarnality of Being. 
${ }^{10}$ Heidegger is quite clear on this: "Life is not a mere Being-present-at-hand, nor is it Dasein. In turn, Dasein is never to be defined ontologically by regarding it as life (in an ontologically indefinite manner) plus something else" (Being and Time 50/75). For commentaries on this infamous passage, see Michel Haar's The Song of the Earth and David Krell's Daimon Life.

${ }^{11}$ If we were thinking in the manner of Aristotle, this domain of Being would certainly be one of time. For Aristotle, time is a numbering or counting of change with respect to before and after (Physics, 219b1). It is precisely this conception of time as one of presence in the 'now' that Heidegger looks to move beyond.

\section{Works Cited}

Callarco, Matthew. "Heidegger's Zoontology." Animal Philosophy: Essential Readings in Continental Thought. Eds. Matthew Callarco and Peter Atterton. New York: Continuum, 2004.

Dastur, Françoise. Heidegger and the Question of Time. Trans. François Raffoul and David Pettigrew. New Jersey: Humanities Press, 1998.

—. Heidegger et la question anthropologique. Louvain-Paris: Éditions Peeters, 2003.

Derrida, Jacques. Of Spirit: Heidegger and the Question. Trans. Geoffrey Bennington and Rachel Bowlby. Chicago: University of Chicago Press, 1989.

—. Aporias. Trans. Thomas Dutoit. Stanford: Stanford University Press, 1993.

—. "'Eating Well', or the Calculation of the Subject." Trans. Peter Connon and Avital Ronnell. Points... Interviews 1974-94. Ed. Elisabeth Weber. Stanford: Stanford University Press, 1995.

-. "The Animal that Therefore I Am (More to Follow)." Trans. David Wills. Critical Inquiry 28 (2002): 369-418.

Elden, Stuart. “Heidegger's Animals.” Continental Philosophy Review 39 (2006): 273-291.

Franck, Didier. "Being and the Living." Trans. Peter T. Connor. Who Comes After the Subject? Eds. Eduardo Cadava, Peter Connor, and Jean-Luc Nancy. New York: Routledge, 1991.

Haar, Michel. The Song of the Earth: Heidegger and the Grounds of the History of Being. Trans. Reginald Lilly. Bloomington, IN: Indiana University Press, 1993. 
Heidegger, Martin. The Basic Problems of Phenomenology. Trans. Albert Hofstadter. Bloomington, IN: Indiana University Press, 1982.

-. History of the Concept of Time: Prolegomena. Trans. Theodore Kisiel. Bloomington, IN: Indiana University Press, 1985.

—. The Concept of Time. Trans. William McNeill. Oxford: Blackwell, 1992.

-. The Fundamental Concepts of Metaphysics: World, Finitude, Solitude. Trans. William McNeill and Nicholas Walker. Bloomington, IN: Indiana University Press, 1995.

—. "On the Essence of Ground." Trans. William McNeill. Pathmarks. Ed. William McNeill. Cambridge: Cambridge University Press, 1998.

—. Being and Time. Trans. John Macquarrie and Edward Robinson. Oxford: Blackwell, 1999.

—. "Wilhelm Dilthey's Research and the Struggle for a Historical Worldview." Trans. Charles Bambach. Supplements: From the Earliest Essays to Being and Time and Beyond. Ed. John van Buren. Albany, NY: SUNY Press, 2002.

Krell, David Farrell. Daimon Life: Heidegger and Life-Philosophy. Bloomington, IN: Indiana University Press, 1992.

McNeill, William. "Life Beyond the Organism: Animal Being in Heidegger's Freiburg Lectures, 1929-30." Animal Others: On Ethics, Ontology, and Animal Life. Ed. H. Peter Steeves. Albany, NY: SUNY Press, 1999.

Merleau-Ponty, Maurice. Phenomenology of Perception. Trans. Colin Smith. New York: Routledge, 1998.

Schalow, Frank. The Incarnality of Being: The Earth, Animals, and the Body in Heidegger's Thought. Albany, NY: SUNY Press, 2006. 